\title{
Neural Responses to Target Features outside a Search Array Are Enhanced during Conjunction but Not Unique-Feature Search
}

\author{
David R. Painter, ${ }^{1}$ Paul E. Dux, ${ }^{2}$ Susan L. Travis, ${ }^{1}$ and Jason B. Mattingley ${ }^{1,2}$ \\ ${ }^{1}$ The University of Queensland, Queensland Brain Institute, St Lucia 4072, Australia, and ${ }^{2}$ The University of Queensland, School of Psychology, St Lucia \\ 4072, Australia
}

\begin{abstract}
The visual world is typically too complex to permit full apprehension of its content from a single fixation. Humans therefore use visual search to direct attention and eye movements to locations or objects of interest in cluttered scenes. Psychophysical investigations have revealed that observers can select target elements from within an array of distractors on the basis of their spatial location or simple features, such as color. It remains unclear, however, how stimuli that lie outside the current search array are represented in the visual system. To investigate this, we recorded continuous neural activity using EEG while participants searched a foveal array of colored targets and distractors, and ignored irrelevant objects in the periphery. Search targets were defined either by a unique feature within the array or by a conjunction of features. Objects outside the array could match the target or distractor color within the array, or otherwise possessed a baseline (neutral) color present only in the periphery. The search array and irrelevant peripheral objects flickered at unique rates and thus evoked distinct frequency-tagged neural oscillations. During conjunction but not unique-feature search, target-colored objects outside the array evoked enhanced activity relative to distractor-colored and neutral objects. The results suggest that feature-based selection applies to stimuli at ignored peripheral locations, but only when central targets compete with distractors within the array. Distractor-colored and neutral objects evoked equivalent oscillatory responses, suggesting that feature-based selection at ignored locations during visual search arises exclusively from enhancement rather than suppression of neural activity.
\end{abstract}

Key words: feature-based attention; frequency tagging; neural oscillations; steady-state visual evoked potential (SSVEP); visual search

\section{Introduction}

For decades researchers have used visual search tasks to better understand how attention gets allocated to locations and objects in cluttered arrays (Treisman and Gelade, 1980; Wolfe, 1994). In a typical search task, observers look for a target item among spatially distributed arrays of distractor elements defined by simple visual features such as orientation, color, and shape. Such searches can be performed covertly, in the absence of eye movements, on the basis of location (spatial attention; e.g., Moran and Desimone, 1985) or visual features (feature-based attention; e.g., Treue and Martínez Trujillo, 1999). Single-unit recordings in nonhuman primates and neuroimaging results from humans suggest that search is controlled via interactions between the visual cortex, which contains a hierarchy of modules tuned to dis-

\footnotetext{
Received Aug. 26, 2013; revised Jan. 19, 2014; accepted Jan. 28, 2014.

Author contributions: D.R.P., P.E.D., S.L.T., and J.B.M. designed research; D.R.P. and S.L.T. performed research; D.R.P., P.E.D., S.L.T., and J.B.M. analyzed data; D.R.P., P.E.D., S.L.T., and J.B.M. wrote the paper.

This work was supported by Australian Research Council (ARC) Discovery Grant DP110102925 to P.E.D. and J.B.M., D.R.P. and S.L.T. were supported by Australian Postgraduate Awards. P.E.D. was supported by an ARC Discovery Grant and APD Fellowship DP0986387, and an ARC Future Fellowship FT120100033. J.B.M. was supported by an ARC Australian Laureate Fellowship FL110100103.

The authors declare no competing financial interests.

Correspondence should be addressed to Dr. David R. Painter, Queensland Brain Institute, University of Queensland, St Lucia, Queensland, 4072, Australia. E-mail: david.ross.painter@gmail.com.

DOI:10.1523/JNEUROSCI.3630-13.2014

Copyright $\odot 2014$ the authors $\quad 0270-6474 / 14 / 343390-12 \$ 15.00 / 0$
}

tinct features of the visual input (Hubel and Wiesel, 1962), and parietal and prefrontal cortices specialized for attentional control (Desimone and Duncan, 1995; Corbetta and Shulman, 2002).

Studies in nonhuman primates have demonstrated space- and feature-based attentional modulation of neural activity during visual search. For example, neurons in area V4 show enhanced responses when stimuli in their receptive fields are selected for saccades, or match targets on the basis of their color or shape (Bichot et al., 2005). During search, frontoparietal networks synchronize their activity with visual cortical areas to highlight target locations and features (Buschman and Miller, 2007; Gregoriou et al., 2009). Results from human neuroimaging studies converge to suggest that frontoparietal networks exert control over visual areas to highlight important features and locations within search arrays (e.g., Donner et al., 2002; Nobre et al., 2003). Thus, spatial and feature-based selection mechanisms act together to enhance neural responses to targets within a search array.

Despite considerable research, it remains unknown how the visual system represents objects that occupy ignored locations. Feature-based attention can act at spatially irrelevant locations (Serences et al., 2005; Andersen et al., 2011), suggesting that current search goals might influence perception outside the immediate search array. It remains unclear, however, which search demands induce feature-based selection outside the array and whether such influences reflect featural enhancement or suppres- 


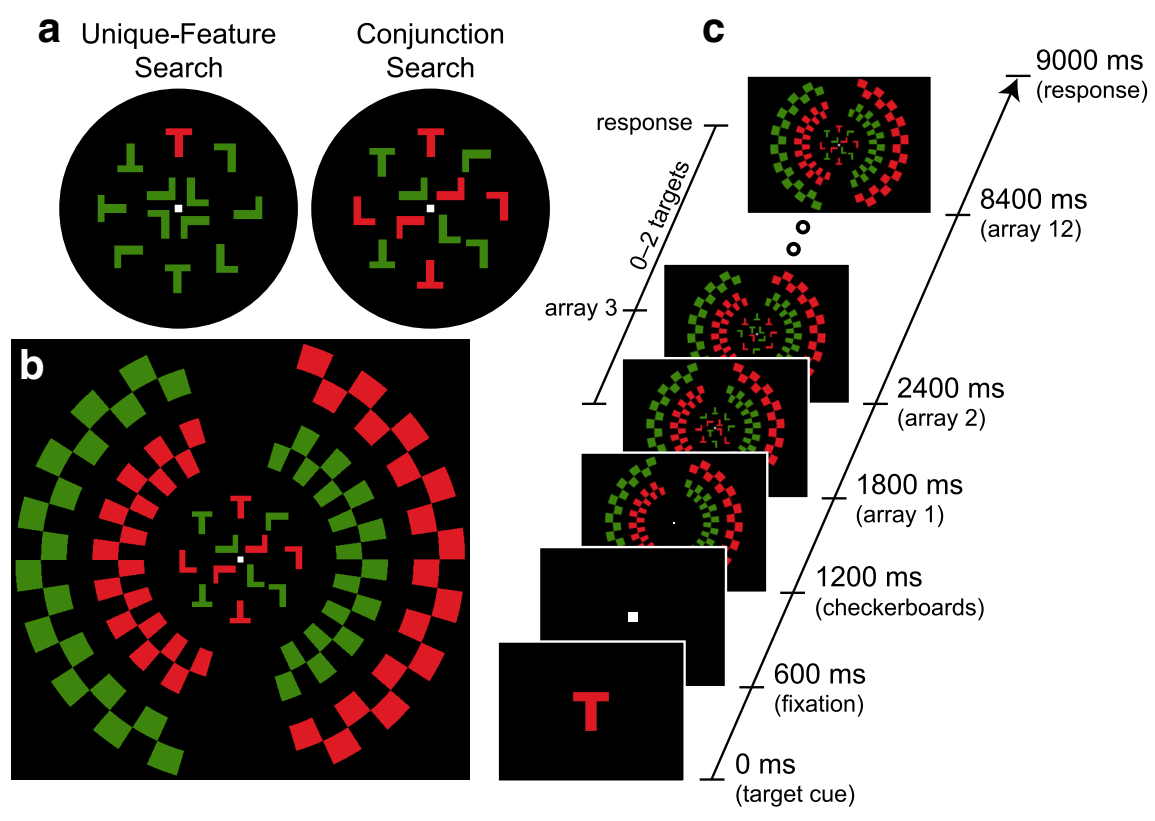

Figure 1. Task diagram for Experiment 1. $\boldsymbol{a}$, Target-present search arrays for the unique-feature and conjunction search tasks. In this example, the cued target color is red, and the uncued distractor color is green. $\boldsymbol{b}$, Stimulus displays. Surrounding the letter arrays in central vision, peripheral checkerboards with cued and uncued colors flickered at unique frequencies (12.5 and $16.7 \mathrm{~Hz}$ ), evoking SSVEPS. c, Trial sequence. Participants monitored a continuous stream of search arrays in central vision to report zero, one, or two occurrences of targets (upright " $\mathrm{T}$ " in the cued color). For illustration, the target cue and fixation box during the fixation period are shown larger than actual size.

sion. Given that no studies have investigated featural selection outside the array (i.e., at ignored locations) during traditional visual search, it remains possible that observers can spatially suppress locations outside the array and thereby limit featural selection to the array itself (e.g., Schwartz et al., 2005).

To address these questions, participants searched for colordefined targets in central vision, and we concurrently measured neural responses to objects presented in peripheral vision. To manipulate search demands, targets were defined either by a single feature or a conjunction of features (easy and difficult searches, respectively) (Wolfe and Horowitz, 2004). To probe neural responses to events outside the search array, peripheral stimuli flickered at unique frequencies, producing steady-state visual evoked potential (SSVEP) oscillations, which were detected using EEG (e.g., Andersen and Müller, 2010). To ensure that attention was spatially focused on the arrays, objects outside the array were completely task-irrelevant and were subject to strong stimulus-driven competition from within the search arrays.

\section{Materials and Methods}

Participants. Twenty different individuals participated in each of two experiments (total $N=40$ ). Mean age (Experiment 1 : mean $=26.90$ years, $\mathrm{SD}=5.66$ years; Experiment $2:$ mean $=25.50$ years, $\mathrm{SD}=3.64$ years) and gender composition (Experiment 1: 7 males; Experiment 2: 9 males) were similar for both experiments. Participants had normal or corrected-to-normal vision and volunteered for the study after providing informed consent. The study was approved by The University of Queensland Human Research Ethics Committee.

Visual search task. In both experiments, participants engaged in visual search for a colored target letter (an upright " $T$ ") among distractor items (inverted and upright "Ts" and rotated "Ls") in central vision while ignoring flickering checkerboards in the periphery (Figs. 1 and 2). Importantly, these checkerboards and their locations were never taskrelevant. The search arrays consisted of 12 letters, and these arrays were updated every $600 \mathrm{~ms}(1.7 \mathrm{~Hz})$ in Experiment 1 , and every $700 \mathrm{~ms}(1.4 \mathrm{~Hz})$ in Experiment 2. Stimuli were presented on an NEC Accusync 120 monitor. In Experiment 1, the monitor was set to run at $100 \mathrm{~Hz}$ with a resolution of $1024 \times$ 768. In Experiment 2, the monitor was set at $160 \mathrm{~Hz}$ with a resolution of $640 \times 480$. Stimulus presentation was controlled using the Cogent 2000 Toolbox (http://www.vislab.ucl.ac. uk/cogent.php) for MATLAB (MathWorks), running under Windows XP. Viewing distance was $57 \mathrm{~cm}$. Stimuli were matched for luminance $\left(17.4 \mathrm{~cd} / \mathrm{m}^{2}\right)$ using a photometer and were presented against a black background (RGB: 0, 0, 0). Letters and checkerboards were red (RGB: 255, 0, 0), green (RGB: 0, 119,0), or gray (RGB: 106, 106, 106).

Each trial consisted of a continuous stream of 12 search arrays and contained zero, one, or two targets with equal probability. In separate blocks, participants were instructed to report the number of targets (upright "T") in the cued target color (Experiment 1: red or green, Fig. $1 c$; Movie 1; Experiment 2: red, green, or gray; Fig. $2 c$; Movie 2) at the end of each trial. Participants were instructed to ignore letters in the uncued distractor color. To ensure that participants maintained their search throughout the trial, target events were distributed across the stream of arrays. On one target and two target trials, the first target appeared between the third and 10th array (inclusive), and the second target appeared within the 11th or 12th array. On two target trials, targets were separated by at least one search array. After offset of the last search array, a response screen prompted participants to indicate how many targets were present (zero, one, or two), and participants responded with an unspeeded key press. After the response, visual feedback was provided (1000 ms; correct/incorrect). Successive trials began immediately after feedback.

In Experiment 1, there were two types of search task, and these were run in separate blocks. In the unique-feature task, search arrays consisted of a single letter in the cued color, and the remaining 11 letters were in the uncued color (Fig. 1a). The single letter in the cued color was present within all arrays, and was an upright " $\mathrm{T}$ " in target-present arrays and an inverted " $\mathrm{T}$ " in target-absent arrays. The 12 letters in each search array were randomly selected and evenly distributed within an imaginary circle $12.8^{\circ}$ in diameter centered at fixation. Letters were presented in Arial font $\left(1.3^{\circ} \times 1.5^{\circ}\right)$. Eight letters were "L," and four were "T." Of the "Ls," equal numbers were upright, inverted, rotated $90^{\circ}$ clockwise, and rotated $90^{\circ}$ counterclockwise. In the conjunction search task, half of the "Ls" and "Ts" were presented in the cued color and the other half were presented in the uncued color (Fig. 1a).

In Experiment 1, the display contained flickering red and green checkerboards in the periphery (Fig. 1b). The checkerboards occupied a region $5.8^{\circ}-13.6^{\circ}$ from fixation, surrounding the central search arrays. The distance between the central search array and the peripheral checkerboards was $1.9^{\circ}$. There were four checkerboards, arranged in spatially separated concentric semicircular inner and outer rings in each hemifield. The inner and outer checkerboards were separated by one concentric ringwidth $\left(1.6^{\circ}\right)$ of blank space and had a radial arc width of $8.2^{\circ}$ of polar angle. The checkerboards were arranged such that the left outer/right inner and left inner/right outer segments were matched for color and flicker frequency. On each trial, the two checkerboards of the same color counterphased either at $12.5 \mathrm{~Hz}$ or $16.7 \mathrm{~Hz}$. The pairings of checkerboard color, position, and flicker frequency were fully counterbalanced across trials within each block. There were 288 trials ( 8 blocks $\times 36$ trials per block), and these were divided into equal numbers of unique-feature and conjunction searches. The cued color was constant within a block, and 
each block lasted $5.4 \mathrm{~min}$, excluding behavioral responses. The block order was randomized.

In Experiment 2, we repeated the conjunction search task from Experiment 1, but with a crucial modification involving the addition of a third color to the peripheral checkerboards. Our rationale was to determine whether feature-based modulation of neural responses to the peripheral checkerboards in Experiment 1 arose from enhancement of the target color or suppression of the distractor color during conjunction search, relative to a neutral baseline. In Experiment 2, we also modified the arrangement of the peripheral checkerboards so that the colors were interleaved in radial arcs around the central search display (Fig. 2a). Flicker was achieved by shifting the checkerboard segments to an adjacent, unoccupied location (clockwise or counterclockwise), and back again. Perceptually, the flickering checkerboards appeared to rotate clockwise and counterclockwise (i.e., twist). This motion was equivalent for each checkerboard color and flicker frequency (Fig. 2b; Movie 2).

On each trial in Experiment 2, the checkerboard color flickered at a unique frequency (7.6, 13.3, or $17.8 \mathrm{~Hz})$. As in Experiment 1, pairings of checkerboard color, position, and flicker frequency were fully counterbalanced across trials within each block. The central search array and the peripheral checkerboards subtended the same visual angles as those in Experiment 1. In separate blocks, participants searched for red, green, or gray targets (zero, one, or two per trial; Fig. 2c). Within blocks, the search arrays consisted of just two colors (red/green, red/gray, or green/gray). Participants searched for an upright " $\mathrm{T}$ " in the cued color and ignored the letters in the uncued color. Thus, the baseline or neutral color always appeared only in the periphery. There were six blocks, corresponding to the six possible cued/uncued/baseline color combinations (Fig. $2 d$ ). There were 216 trials ( 6 blocks $\times 36$ trials per block). The cued, uncued, and baseline colors were held constant within a block. Each block lasted $6.3 \mathrm{~min}$, excluding behavioral responses. All other aspects of the task design were the same as those for Experiment 1.

EEG recording. Continuous EEG data were recorded using a BioSemi Active Two system (BioSemi) and were digitized at a sample rate of 1024 $\mathrm{Hz}$ with 24-bit $\mathrm{A} / \mathrm{D}$ conversion. The 64 active scalp $\mathrm{Ag} / \mathrm{AgCl}$ electrodes were arranged according to the international standard 10-20 system for electrode placement (Oostenveld and Praamstra, 2001) using a nylon head cap. The electrode positions were as follows: AF3, AF4, AF7, AF8, $\mathrm{AFz}, \mathrm{C} 1, \mathrm{C} 2, \mathrm{C} 3, \mathrm{C} 4, \mathrm{C} 5, \mathrm{C} 6, \mathrm{CP} 1, \mathrm{CP} 2, \mathrm{CP} 3, \mathrm{CP} 4, \mathrm{CP} 5, \mathrm{CP} 6, \mathrm{CPz}, \mathrm{Cz}, \mathrm{F} 1$, F2, F3, F4, F5, F6, F7, F8, FC1, FC2, FC3, FC4, FC5, FC6, FCz, FP1, FP2, FPz, FT7, FT8, Fz, Iz, O1, O2, Oz, P1, P10, P2, P3, P4, P5, P6, P7, P8, P9, PO3, PO4, PO7, PO8, POz, Pz, T7, T8, TP7, and TP8. As per BioSemi system design, the common mode sense and driven right leg electrodes served as the ground, and all scalp electrodes were referenced to the common mode sense during recording. Eye movements were monitored online using bipolar horizontal electro-oculographic (EOG) electrodes placed at the outer canthi of each eye and bipolar vertical EOG electrodes placed above and below the left eye.

EEG analysis. Offline EEG analysis was performed using Brain Electrical Source Acquisition (BESA 5.3; MEGIS Software), the EEGLAB Toolbox (Delorme and Makeig, 2004) for MATLAB, and custom-written MATLAB functions. BESA was used to inspect the data, perform prepro-
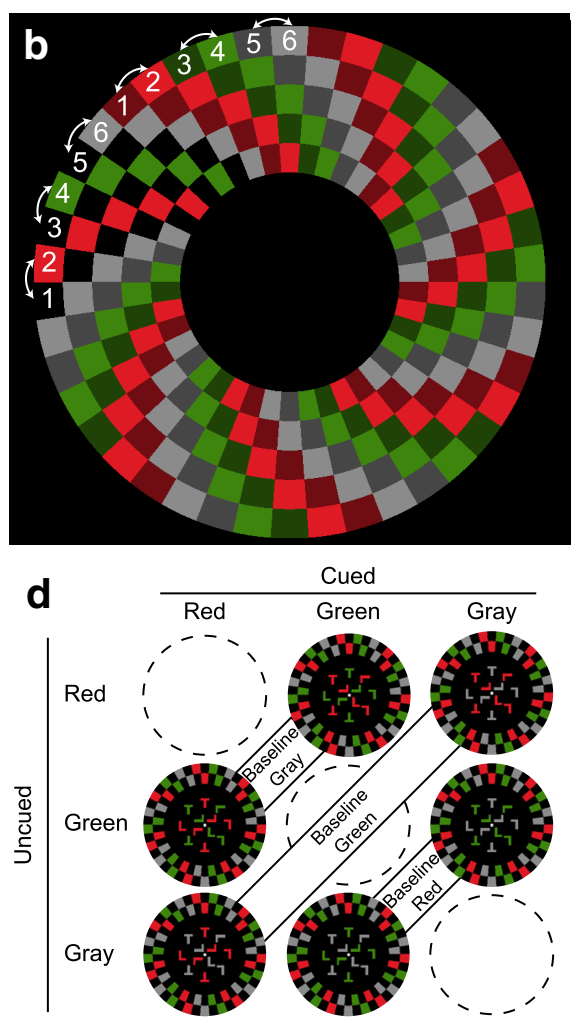

Figure 2. Task diagram for Experiment 2. a, Stimulus displays. Participants performed conjunction searches for red, green, and gray targets. The cued and uncued colors appeared both in the central search arrays and in the peripheral checkerboards. The

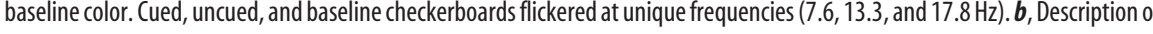
eckerboard displays. During the trial, each checkerboard color could occupy one of two adjacent positions. In this example, red

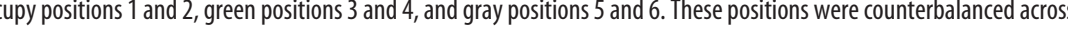
here by blank (background) space and also by a second color of the same hue (dark red, dark green, and dark gray). When one color adjacent but nonoverlapping locations. c, Trial sequence. The trial sequence was identical to that used in Experiment 1.d, Color combinations. In separate blocks of trials, red, green, and gray colors acted as cued, uncued, and baseline colors. Stimulus color (red, green, and gray) was therefore completely counterbalanced with color category (cued, uncued, baseline).

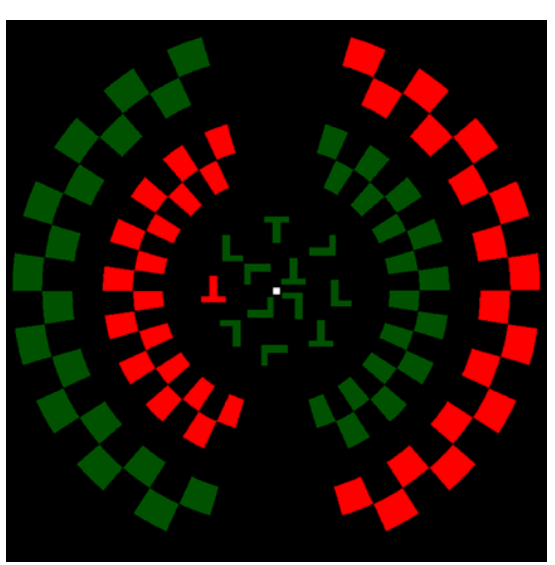

Movie 1. Example trial of the unique-feature search task used in Experiment 1. At the beginning of the trial, the search target is displayed centrally (in this example, an upright red " $\mathrm{T}^{\prime \prime}$ ). Flickering red and green checkerboards then appear in the periphery (here at 16.7 and $12.5 \mathrm{~Hz}$, respectively), followed by the central search arrays. In this example, targets (upright red "Ts") appear in the ninth and 11 th search arrays. 


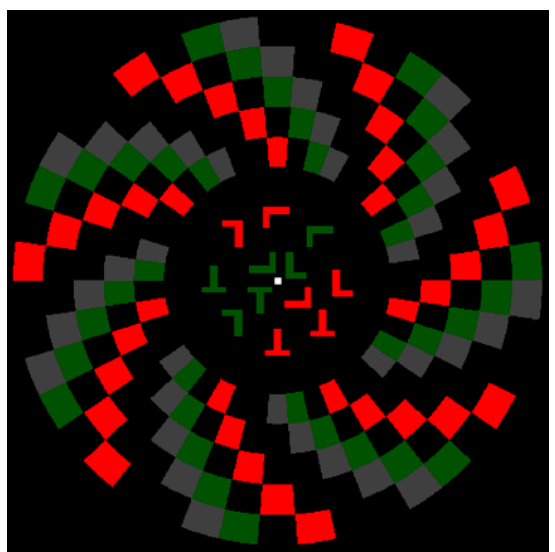

Movie2. Example trial of the conjunction search task used in Experiment 2. At the beginning of the trial, the search target is displayed centrally (in this example, an upright red " $T$ "). Flickering red, green, and gray checkerboards then appear in the periphery (here at 17.7, 13.3, and $7.6 \mathrm{~Hz}$, respectively). In this example, targets (upright red "Ts") appear in the seventh and 11th arrays.

cessing, and extract event-related potentials (ERPs). MATLAB was used for all other analyses. Noisy scalp electrodes, identified via visual inspection, were replaced by a spherical spline interpolation of the voltages recorded at all other scalp electrodes. Each scalp electrode was referenced offline to the average of all 64 scalp electrodes and was subjected to a 0.1 $\mathrm{Hz}$ high-pass digital filter. The EOG electrodes were referenced offline into bipolar vertical and horizontal EOG channels. EEG data were blinkcorrected using an average blink template.

To investigate neural responses evoked by the central search arrays in Experiment 1, we extracted ERPs separately for unique-feature and conjunction search trials (search arrays 1-12, inclusive). ERPs reflected an average of 1728 arrays ( 144 trials $\times 12$ arrays per trial). To identify time points and electrodes for ERP peak analyses, we identified a cluster of four occipitoparietal electrodes that showed maximal frequency domain amplitudes at the search array rate $(1.7 \mathrm{~Hz})$ as revealed via an FFT (duration $6 \mathrm{~s}$; search arrays $3-12$, inclusive). To determine time points for analysis, we visually identified the most pronounced peaks on the grand average ERP. Each peak was summarized as the mean across the four electrodes showing the largest amplitudes. These electrodes were chosen separately for each peak. All scalp topographies were constructed using the standard EEGLAB topoplot function in conjunction with the MATLAB natural neighbor, 2D interpolation method (Sibson, 1981).

To investigate neural responses evoked by the peripheral flickering checkerboards in both experiments, the EEG data were segmented into epochs corresponding to the period within each trial between search arrays 3-12, inclusive ( $6 \mathrm{~s}$ for Experiment 1; $7 \mathrm{~s}$ for Experiment 2). This period was selected to isolate the checkerboard-evoked responses after they reached steady-state oscillation (Morgan et al., 1996). Epochs were averaged for each condition of interest to create grand averages for each participant.

In both experiments, SSVEP amplitudes were extracted from the epochs of interest by applying FFTs and retrieving amplitudes at the fundamental checkerboard flicker frequencies $\left(f_{0} \mathrm{~s}\right)$. To determine the electrodes for analysis, we identified a cluster of four occipitoparietal electrodes that showed maximal responses at $f_{0}$ using an FFT on the grand ERP averaged across search conditions and participants. In Experiment 1 , we extracted four epochs created by crossing search type (unique-feature, conjunction) and color (cued, uncued) factors. In Experiment 2, we extracted six epochs in which one $f_{0}$ was associated with the cued color, and the other two $f_{0}$ s were associated with the uncued and baseline colors. The six cued/uncued/baseline $(\mathrm{Hz})$ epochs were as follows: (1) 7.6/13.3/17.8, (2) 7.6/17.8/13.3, (3) 13.3/7.6/17.8, (4) 13.3/17.8/ 7.6 (5) $17.8 / 7.6 / 13.3$, and (6) $17.8 / 13.3 / 7.6$. We then averaged these epochs to derive SSVEP amplitudes for each frequency when it was associated with the cued, uncued, and baseline colors.
To investigate attentional selection during unique-feature search in Experiment 1, we created averaged ERPs separately for arrays in which the cued feature appeared on the left or right side of the array (corresponding to the central portions of the left and right hemifields, respectively; $\sim 720$ arrays each). The majority of these arrays were target-absent $(\sim 92 \%)$. For the purposes of this analysis only, we excluded arrays in which the cued feature appeared on the vertical midline ( $\sim 288$ arrays), for which no lateralized ERP was expected. The total number of trials per condition provided above is only approximate, as the location of the cued feature was randomized within each array. Epochs were defined from array onset to array offset $(600 \mathrm{~ms})$. To investigate oscillatory $\theta$ amplitudes, we applied Morlet wavelet time-frequency analyses to the lateralized ERPs (for overview, see Farge, 1992; Herrmann et al., 2013). A Morlet wavelet is a tapered sinusoid, constructed by modulating a sine wave with a Gaussian envelope. Convolution of the wavelet with the ERP time series provides a measure of overlap between the signals. Convolution is performed with a wavelet scaled for each frequency of interest. From the FieldTrip toolbox (Oostenveld et al., 2011) for MATLAB, we used the ft_specest_wavelet function, which provides two free parameters: the wavelet width (number of cycles) and the Gaussian width (SDs of the wavelet width). These parameters collectively control the shape of the wavelet and thus determine the trade-off between temporal and spectral resolution. In general, lower values for both parameters produce shorter wavelets, which have better temporal precision but poorer spectral precision relative to longer wavelets. To investigate $\theta$ amplitudes, we used short wavelets (wavelet width $=1.5$, Gaussian width $=2 \mathrm{SD}$ ) to maximize temporal precision. The wavelet transformation was computed from 2 to $14 \mathrm{~Hz}$ at $0.1 \mathrm{~Hz}$ intervals. The ERPs were zero-padded to $10 \mathrm{~s}$ in length to provide adequate information for the analysis. Statistical tests were performed on mean $\theta$ amplitudes $(6-8 \mathrm{~Hz})$ using a permutation method that adjusts $p$ values to control the family-wise error rate for each contrast (Blair and Karniski, 1993). For this purpose, we used the mult_comp_perm_t1 function from the MATLAB File Exchange (Groppe et al., 2011a, b).

In Experiment 2, to assess whether there were periods of transient suppression of the uncued color relative to the baseline color, we used Morlet wavelet time-frequency analyses. Wavelet settings were chosen based on the grand average ERP to maximize the separation between the $f_{0} s$ and the search arrays' harmonics. Therefore, long wavelets were used (wavelet width $=80$, Gaussian width $=24 \mathrm{SD}$ ). A 10.5 s epoch from the onset of the attentional cue to the end of the trial was selected, downsampled to $50 \mathrm{~Hz}$, and zero-padded to $100 \mathrm{~s}$ in length. Wavelets were computed at $0.1 \mathrm{~Hz}$ intervals between 5 and $20 \mathrm{~Hz}$ separately for the four occipitoparietal electrodes showing maximal FFT responses at $f_{0}$ in the main FFT analysis, above. Resulting coefficient amplitudes were then averaged across electrodes and over the range $f_{0} \pm 0.24 \mathrm{~Hz}$. Significance tests were performed on the period from checkerboard onset to the end of the trial using the permutation method cited above.

Statistical tests were performed using MATLAB and IBM SPSS Statistics for Macintosh Version 21.0 (IBM). An $\alpha$ level of 0.05 was used as the significance criterion. For repeated-measures ANOVAs, sphericity was verified using Mauchly's test. Nondirectional $t$ tests were conducted, and the Bonferroni correction for multiple comparisons was used where appropriate.

\section{Results}

\section{Experiment 1}

Behavioral performance on the unique-feature and conjunction search tasks

Accuracy (\% correct) data were submitted to a repeatedmeasures ANOVA with search type (unique-feature, conjunction) and cued color (red, green) as factors. Accuracy was significantly higher for unique-feature search (mean $=94.38$, $\mathrm{SE}=1.54)$ than for conjunction search (mean $=73.40, \mathrm{SE}=$ 3.08; search type: $\left.F_{(1,19)}=72.13, p<0.001, \eta^{2}=0.79\right)$, but accuracy in both tasks was well above chance (i.e., 33\%). There was no significant difference in accuracy between search for red targets $($ mean $=83.43, \mathrm{SE}=2.14)$ and green targets $($ mean $=$ 
84.34, $\mathrm{SE}=2.09$; cued color: $F_{(1,19)}=$ $\left.2.86, p=0.107, \eta^{2}=0.13\right)$ and no significant search type by cued color interaction $\left(F_{(1,19)}=0.09, p=0.769, \eta^{2}=0.00\right)$. As there was no reliable effect of cued color on behavioral performance (and as EEG results for both colors were similar), all subsequent analyses were pooled across this factor.

\section{Neural activity during unique-feature and} conjunction search

Separate analyses were conducted on the neural responses to the central search arrays and the peripheral checkerboards. Analyses of the central array-evoked activity were conducted to test for consistency with previous ERP investigations of visual search. FFT analyses showed that the search array frequency $(1.7 \mathrm{~Hz})$ produced maximal responses over occipitoparietal electrodes. The average time series of $\mathrm{PO} 8, \mathrm{Iz}, \mathrm{O} 2$, and $\mathrm{P} 10$ electrodes was therefore selected for further analysis. SSVEP amplitudes $(\mu \mathrm{V})$ at the search array frequency did not differ significantly between unique-feature $($ mean $=1.82, \mathrm{SE}=$ $0.15)$ and conjunction search (mean $=1.92$, $\left.\mathrm{SE}=0.17 ; t_{(19)}=-0.69, p=0.489\right)$.

Strong ERPs were evoked over the occipitoparietal electrode cluster for both unique-feature and conjunction search tasks. Five prominent peaks were identified: P1, N1, N2, N3, and P2 (Fig. 3a). Both unique-feature and conjunction search arrays elicited a positivity that peaked at $\sim 100 \mathrm{~ms}(\mathrm{P} 1)$, followed by a negativity that peaked at $\sim 200 \mathrm{~ms}(\mathrm{~N} 2)$. Thereafter, the unique-feature search ERP rapidly returned to a positive peak $(\mathrm{P} 2)$, whereas the conjunction search ERP remained negative until $\sim 400 \mathrm{~ms}$ after array onset. This divergence in the ERPs $\sim 200-$ $400 \mathrm{~ms}$ after the stimulus is consistent with previous reports and is thought to reflect the increased attentional demands of conjunction search relative to unique-feature search (Luck et al., 1993; Luck and Hillyard, 1995; Soria and Srebro, 1996; Cortese et al., 1999; Leonards et al., 2003; Wolber and Wascher, 2003).

To assess these patterns, four electrodes that showed maximal responses on the grand mean ERP for each peak were selected for analysis (Fig. 3b). The electrodes were as follows: PO8, PO4, O1, P6 (P1 peak); Oz, O2, Iz, O1 (N1 peak); PO8, O2, Iz, Oz (N2 peak); P10, Iz, P8, PO8 (N3 peak); and PO4, PO8, O2, P10 (P2 peak). Peak amplitudes $(\mu \mathrm{V})$ averaged across the four electrodes were submitted to a repeated-measures ANOVA with the factors of search type (unique-feature, conjunction) and ERP peak ( $\mathrm{P} 1$, N1, N2, N3, P2). There were significant main effects of both factors (search type: $F_{(1,19)}=16.45, p=0.001, \eta^{2}=0.46$; ERP peak: $\left.F_{(4,76)}=42.84, p<0.001, \eta^{2}=0.69\right)$, in addition to a significant interaction between them $\left(F_{(4,76)}=37.49, p<0.001\right.$, $\eta^{2}=0.66$; Fig. $3 c$ ). This interaction was assessed using post hoc tests to compare the effects of search type for each peak. The P1 peak was significantly larger for conjunction search compared with unique-feature search $\left(t_{(19)}=-3.78, p=0.001\right)$. Search type did not significantly affect the N1 or N2 peaks $\left(t_{(19)}>-0.31\right.$, $p>0.76$ ), but the $\mathrm{N} 3$ and $\mathrm{P} 2$ peaks were significantly more negative for conjunction search compared with unique-feature search $\left(t_{(19)}>6.63, p<0.001\right)$. Together, the results of the ERP analyses on the central search arrays revealed that both earlier (i.e., P1) and later (i.e., N3, P2) peaks differed between uniquefeature and conjunction searches. The difference between the tasks was numerically larger at later peaks, consistent with previous ERP investigations of visual search (Luck et al., 1993; Luck and Hillyard, 1995; Soria and Srebro, 1996; Cortese et al., 1999; Leonards et al., 2003; Wolber and Wascher, 2003). The P1 effect additionally showed that search demands influenced early search-array evoked neural responses.

The key question addressed in our study was how search demands within the array influenced the perception of objects outside the array, as indexed via SSVEP amplitude. The peripheral checkerboards evoked strong SSVEPs at occipitoparietal electrode sites (Fig. 4a), consistent with previous frequency-tagging studies of selective attention (e.g., Kim et al., 2007; Andersen et al., 2012). During conjunction search, SSVEP amplitudes were higher for the cued color than for the uncued color (Fig. 4b). Amplitudes appeared to be similar for both colors during unique-feature search. To assess these patterns, SSVEP amplitudes were averaged over $\mathrm{POz}, \mathrm{Oz}, \mathrm{O} 1$, and $\mathrm{O} 2$ electrodes, which 


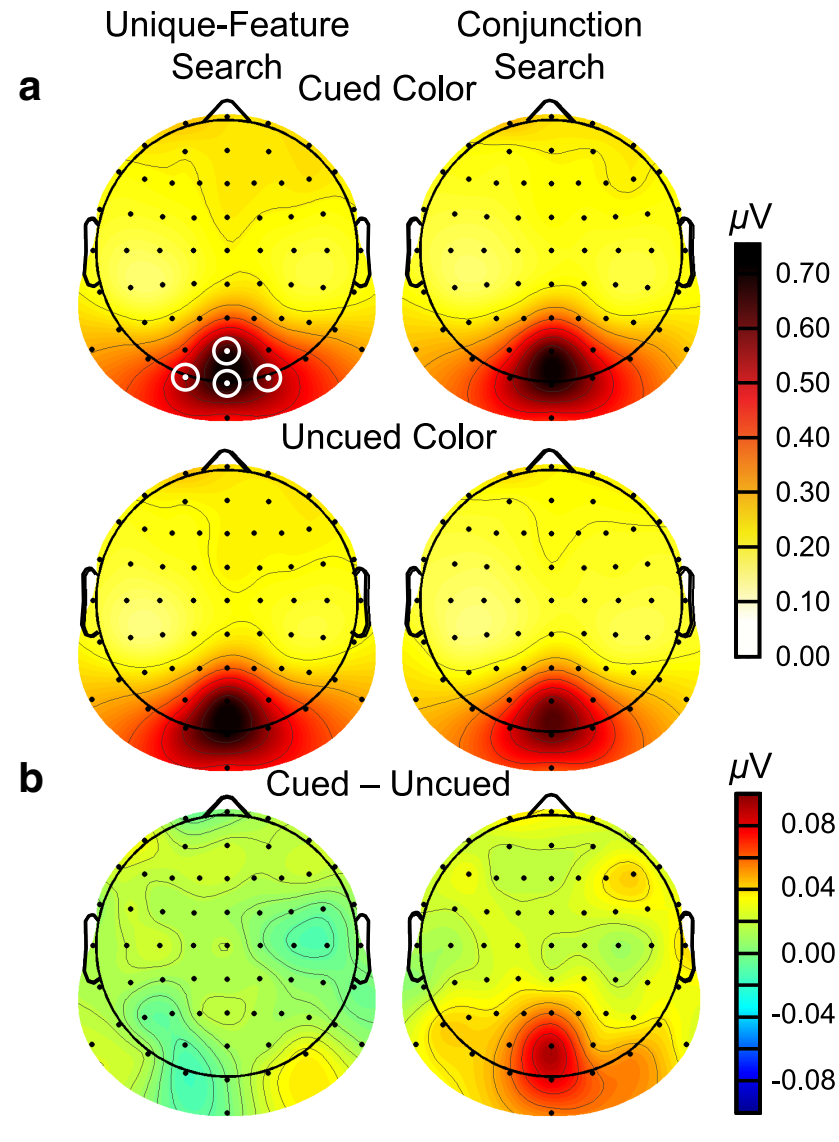

Figure 4. Spline-interpolated isocontour SSVEP amplitude topographies assessed via FFTs for Experiment 1. Amplitudes are averaged across the fundamental checkerboard flicker frequencies ( 12.5 and $16.7 \mathrm{~Hz}$ ) and cued red and green conditions. $\boldsymbol{a}$, SSVEP amplitude topographies. $\boldsymbol{b}$, SSVEP amplitude contrast topographies.

showed the highest amplitudes on the grand average ERP for both 12.5 Hz and $16.7 \mathrm{~Hz}$ checkerboard frequencies.

These patterns were confirmed statistically using a repeatedmeasures ANOVA on SSVEP amplitude $(\mu \mathrm{V})$ with the factors of search type (unique-feature, conjunction), color (cued, uncued), and frequency $(12.5 \mathrm{~Hz}, 16.7 \mathrm{~Hz})$. The search effect was significant, showing that SSVEP amplitudes were significantly higher during unique-feature search (mean $=0.66, \mathrm{SE}=0.11$ ) than during conjunction search (mean $=0.61, \mathrm{SE}=0.09 ; F_{(1,19)}=$ 5.10, $p=0.036, \eta^{2}=0.21$ ). This result is consistent with the well-established finding that task-irrelevant distractors receive less processing during tasks involving high perceptual load, such as conjunction search (Lavie, 1995; Schwartz et al., 2005). The color by frequency and the search by color by frequency interactions were also significant $\left(F_{(1,19)}>9.85, p<0.005, \eta^{2}>0.34\right.$; Fig. 5). These effects were followed up by a repeated-measures ANOVA for each search type with color and frequency as factors. For unique-feature search, there were no significant main effects or interaction $\left(F_{(1,19)}<0.13, p>0.722, \eta^{2}<0.01\right)$, indicating that SSVEP amplitudes were not influenced by color or frequency (Fig. 5a). For conjunction search, there were no significant main effects of frequency or color $\left(F_{(1,19)}<2.86, p>0.107, \eta^{2}<0.13\right)$, but there was a significant interaction between these factors $\left(F_{(1,19)}=11.21, p=0.003, \eta^{2}=0.37\right.$; Fig. $\left.5 b\right)$. At $12.5 \mathrm{~Hz}$, amplitudes were significantly higher for checkerboards with the cued color $($ mean $=0.64, \mathrm{SE}=0.12)$ than with the uncued color (mean $\left.=0.54, \mathrm{SE}=0.10 ; t_{(19)}=2.89, p=0.009\right)$. A similar effect was present at $16.7 \mathrm{~Hz}$. Again, amplitudes were significantly
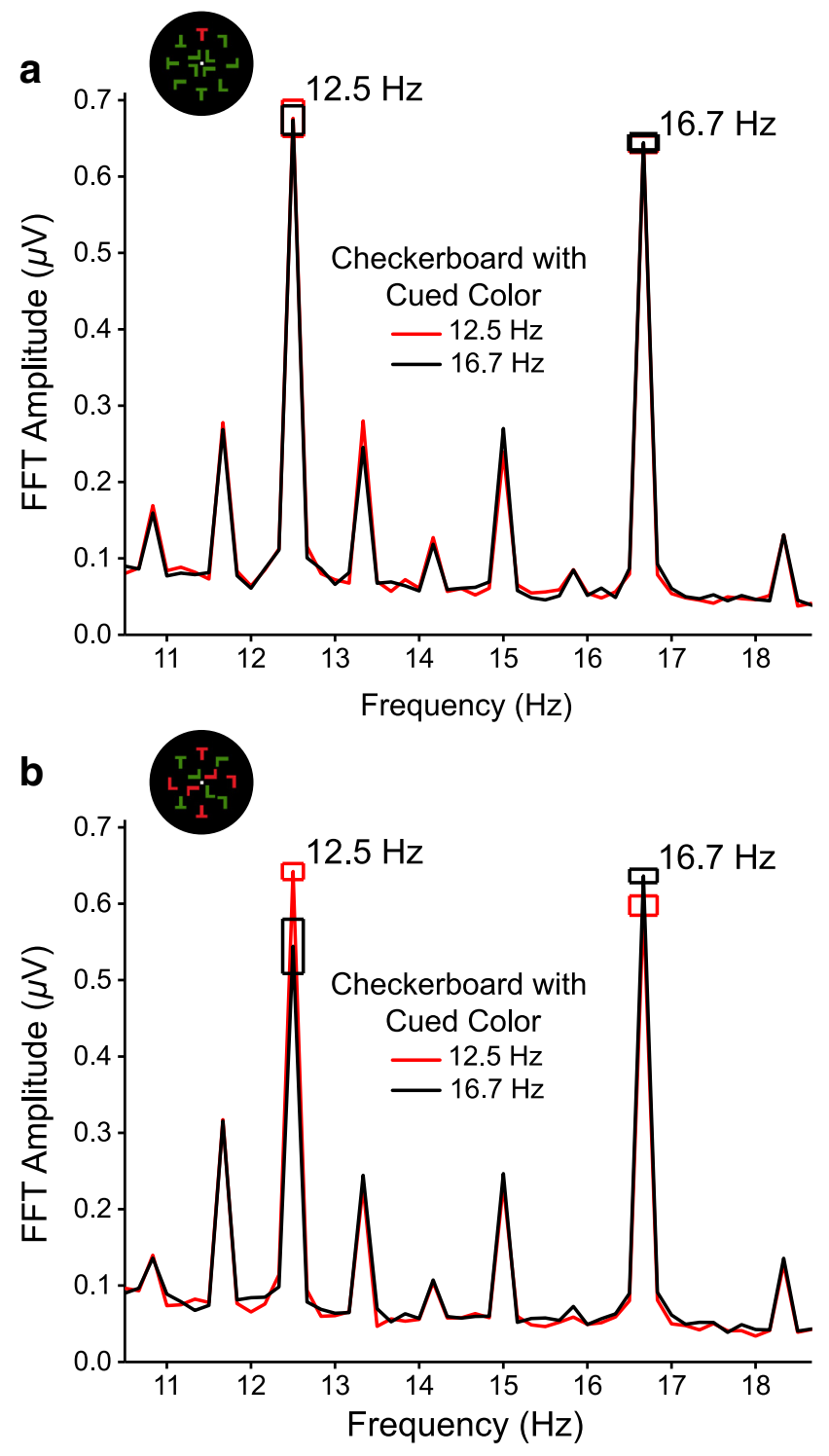

Figure 5. Checkerboard-evoked SSVEP amplitudes assessed via FFTs for Experiment 1. FFT amplitude spectra are averaged across a cluster of four occipitoparietal electrodes and cued red and green conditions. Frequency spikes are located at the fundamental checkerboard frequencies and the search array harmonics. Error boxes indicate within-subjects SE. $\boldsymbol{a}$, Unique-feature search. FFT spectra for the cued 12.6 and $16.7 \mathrm{~Hz}$ frequencies overlap almost completely and therefore are statistically indistinguishable. $\boldsymbol{b}$, Conjunction search.

higher for checkerboards with the cued color $($ mean $=0.64, \mathrm{SE}=$ 0.12 ) than for those with the uncued color (mean $=0.60, \mathrm{SE}=$ $\left.0.11 ; t_{(19)}=2.25, p=0.036\right)$. These results are consistent with previous reports of feature-based modulation of SSVEPs (Andersen et al., 2008; Andersen and Müller, 2010) but importantly extend those reports by showing that feature-based attention outside the array depends on the demands of the visual search task. All other effects were nonsignificant $\left(F_{(1,19)}<2.49, p>\right.$ $\left.0.131, \eta^{2}<0.12\right)$.

The absence of evidence for any reliable feature-based selection of the peripheral checkerboards in the unique-feature search task raises the question of whether feature-based selection operated within the central search arrays themselves. To address this question, we first examined the N2pc, an ERP marker of attentional allocation (Luck and Hillyard, 1994a, b). The N2pc appears at posterior electrode sites, contralateral to the search target, at 
$\sim 150-300$ ms after the stimulus (Sawaki et al., 2012). We created ERPs for arrays in which the cued feature appeared in the left and right visual hemifields and calculated the mean N2pc amplitude centered at the point of maximum divergence between contralateral and ipsilateral waveforms (240-260 ms), averaged over PO7 and PO8 electrodes (Fig. 6a). The contrast between topographies for left and right hemifield arrays verified that the $\mathrm{N} 2 \mathrm{pc}$ was indeed maximal at $\mathrm{PO} 7$ and $\mathrm{PO} 8$ electrodes (Fig. 6c), consistent with previous reports (Sawaki et al., 2012; e.g., Dowdall et al., 2012).

To assess these results statistically, N2pc amplitudes $(\mu \mathrm{V})$ were submitted to a repeated-measures ANOVA, with electrode (PO7, PO8) and cued feature hemifield (left, right) as factors. The main effect of hemifield was nonsignificant $\left(F_{(2,38)}=\right.$ 0.677, $\left.p=0.421, \eta^{2}=0.03\right)$, as was the main effect of electrode $\left(F_{(1,19)}=0.04\right.$, $\left.p=0.848, \eta^{2}=0.00\right)$, but there was a significant hemifield $\times$ electrode interaction $\left(F_{(2,38)}=58.48, p<0.001, \eta^{2}=0.76\right.$; Fig. $6 e$ ). To examine this interaction, we conducted paired-samples $t$ tests on the effects of cued feature location for each electrode. N2pc amplitudes at PO8 were significantly higher when the cued feature appeared in the contralateral (left) than in the ipsilateral (right) hemifield $\left(t_{(19)}=\right.$ $-6.84, p<0.001$ ). Similarly, N2pc amplitudes at PO7 were significantly higher when the cued feature appeared in the contralateral (right) compared with ipsilateral (left) hemifield $\left(t_{(19)}=6.70, p<\right.$ 0.001). At both electrodes, therefore, $\mathrm{N} 2 \mathrm{pc}$ amplitudes were significantly higher when the cued feature appeared in the contralateral versus ipsilateral hemifield, suggesting that attention was allocated to the location of the cued feature within the central array.

Because both top-down control and bottom-up stimulus salience can influence N2pc amplitudes (Hickey et al., 2006; Eimer and Kiss, 2008; Lien et al.,

2008), the relative contributions of these factors remain unclear from the N2pc analyses described above. To disentangle their contributions, we investigated oscillatory $\theta$ amplitudes, which have recently been linked with attention shifts during visual search (Dowdall et al., 2012). To this end, we isolated ERP waveforms contralateral and ipsilateral to the cued feature, averaged over PO7 and PO8 electrodes (and over left and right visual hemifield cued feature locations). Morlet wavelet time-frequency analyses from 2 to $14 \mathrm{~Hz}$ showed a relatively selective increase in oscillatory power within $\delta(2-4 \mathrm{~Hz})$ and $\theta(4-8 \mathrm{~Hz})$ frequency bands from $\sim 100 \mathrm{~ms}$ after array onset (Fig. $6 b$ ). This increase in oscillatory power was larger at contralateral than ipsilateral electrode sites.

To assess this pattern statistically, we focused on a subset of the $\theta$ range $(4-6 \mathrm{~Hz})$ that has previously been linked with attenwithin-subjects SE. b

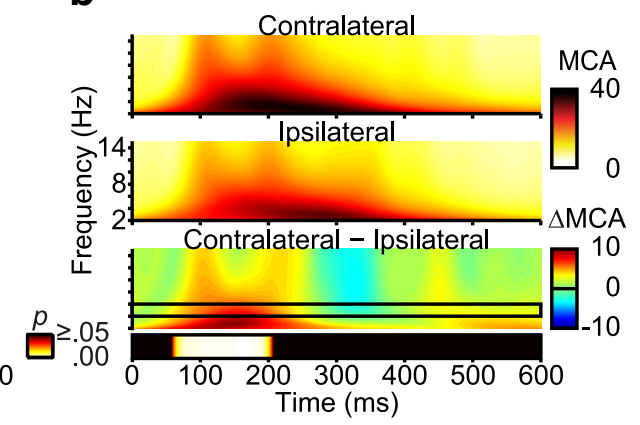

d

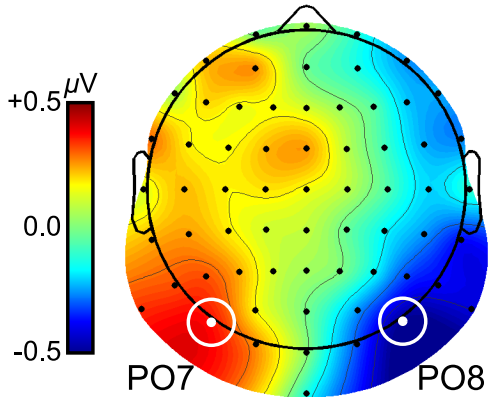

$\mathbf{f}$

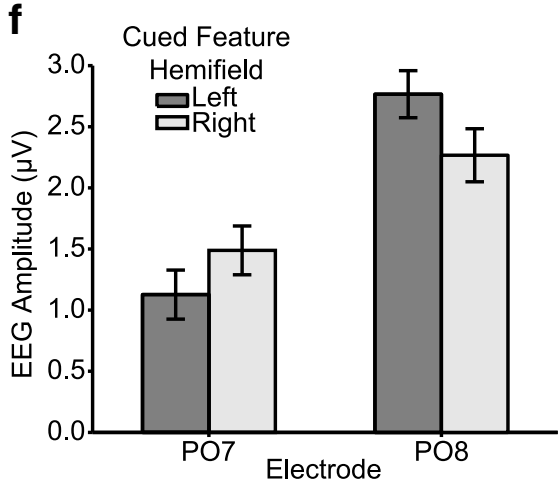

Figure 6. Attentional selection within the central array during unique-feature search in Experiment 1. $\boldsymbol{a}$, ERP traces averaged over P07 and P08 electrodes. N2pc and P1 analysis epochs are highlighted in yellow. Permutation test results for the contralateral minus ipsilateral contrast are presented at the bottom. Only significant differences corrected for family-wise error rate are presented ( $p<0.05$ ). $\boldsymbol{b}$, Wavelet heat maps as a function electrode site (contralateral, ipsilateral), averaged over P07 and P08 ). Permutation test results for this contrast are presented at the bottom. c, Scalp topography during the N2pcepoch created by tracting ERPs for left hemifield cued features from ERPs for right hemifield cued features. This plotting convention allows

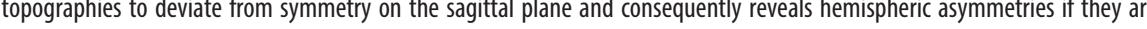
hemifield $f$ P1 amplitudes as a function of electode and

tion shifts (Dowdall et al., 2012). A permutation test showed that $\theta$ amplitudes (Morlet wavelet coefficient; MCA) were significantly higher at the electrode site contralateral than ipsilateral to the cued feature, from $\sim 60-210 \mathrm{~ms}$ after array onset. This result suggests that selection of the target feature began quite early after the appearance of the central search array.

Although both top-down control and bottom-up salience can influence N2pc amplitudes (Hickey et al., 2006; Eimer and Kiss, 2008; Lien et al., 2008), only top-down control seems to influence the amplitude of early electrophysiological components, such as the P1 peak (Hillyard and Münte, 1984; Zhang and Luck, 2009; Moher et al., 2014). To investigate whether the cued feature location influenced $\mathrm{P} 1$ peak amplitudes, we performed a permutation test on the difference between ERP time courses contralat- 
eral and ipsilateral to the cued feature, averaged across PO7 and PO8 electrodes (Fig. 6a). The ERP was significantly more negative at contralateral relative to ipsilateral electrode sites $\sim 185$ $350 \mathrm{~ms}$ after array onset, consistent with the N2pc results reported above. Moreover, the ERP was significantly more positive at contralateral relative to ipsilateral sites $\sim 100-130 \mathrm{~ms}$ after array onset, suggesting that the P1 component was also affected by the location of the cued feature within the central array. The contrast between topographies for left and right hemifield arrays verified that the $\mathrm{P} 1$ difference was maximal at the $\mathrm{PO} 7$ and $\mathrm{PO} 8$ electrode sites (Fig. 6d).

To confirm this result, we performed a repeated-measures ANOVA on P1 amplitudes $(\mu \mathrm{V})$ with cued-feature hemifield (left, right) and electrode (PO7, PO8) as factors. The effect of hemifield was nonsignificant $\left(F_{(1,19)}=1.19, p=0.289, \eta^{2}=\right.$ $0.06)$. There was, however, a significant electrode effect $\left(F_{(1,19)}=\right.$ $6.85, p=0.017, \eta^{2}=0.265$ ), indicating that $\mathrm{P} 1$ amplitudes were reliably higher at PO8 than at PO7. Critically, there was also a significant hemifield by electrode interaction $\left(F_{(1,19)}=19.08, p<\right.$ $0.001, \eta^{2}=0.50$; Fig. $6 f$ ). At electrode PO8, P1 amplitudes were significantly higher when the cued feature was in the contralateral (left) hemifield compared with the ipsilateral (right) hemifield $\left(t_{(19)}=3.70, p=0.002\right)$. Likewise, at electrode PO7, P1 amplitudes were significantly higher when the cued feature was in the contralateral (right) hemifield compared with ipsilateral (left) hemifield $\left(t_{(19)}=-3.33, p=0.004\right)$. At both electrodes, therefore, P1 amplitudes were higher when the cued feature was in the contralateral versus ipsilateral hemifield.

To summarize, the analyses of evoked responses to the unique feature within the central search array revealed enhanced N2pc, $\theta$, and P1 amplitudes at contralateral relative to ipsilateral electrode sites. Together, these results strongly imply that there was top-down attentional selection within the unique-feature search arrays (Hillyard and Münte, 1984; Zhang and Luck, 2009; Moher et al., 2014), despite there being no evidence for feature-based selection outside these arrays. Overall, therefore, the findings of Experiment 1 suggest that feature-based attention applies outside a search array during conjunction but not unique-feature search.

What remains unclear from Experiment 1, however, is whether the observed feature-based modulation during conjunction search reflects enhancement of the cued color, suppression of the uncued color, or a combination of enhancement and suppression (Treue and Martínez Trujillo, 1999; Andersen and Müller, 2010; Bridwell and Srinivasan, 2012; Moher et al., 2014). To address this issue, in Experiment 2, we compared SSVEP amplitudes evoked by three sets of checkerboards outside the central array during conjunction search: (1) those whose color matched that of the cued target; (2) those whose color matched that of the uncued distractor; and (3) those in a third color that matched neither the target nor the distractor color from the central search array, and thus could be used as reference/baseline in subsequent analyses (Fig. 2a). On each trial, cued, uncued, and baseline checkerboards flickered at unique frequencies (7.6, 13.3, and 17.8 $\mathrm{Hz}$ ), allowing us to isolate responses for each color category.

\section{Experiment 2}

Behavioral performance on the conjunction search task

Accuracy (\% correct) data for the conjunction search task were submitted to a repeated-measures ANOVA with cued color as the factor. Conjunction search performance was comparable to that observed in Experiment 1 (i.e., mean $=73.40, \mathrm{SE}=3.08$ ) and did not differ significantly between red (mean $=77.57, \mathrm{SE}=2.87$ ), green $($ mean $=78.89, \mathrm{SE}=2.68)$, and gray targets $($ mean $=$

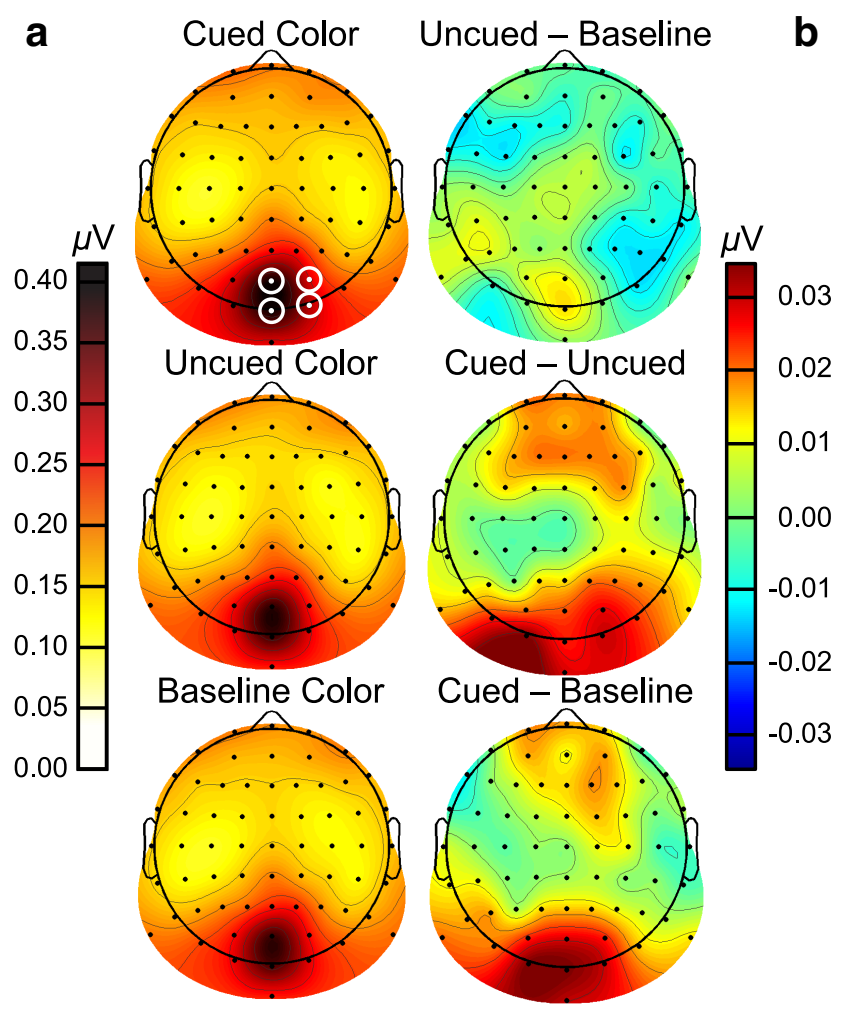

Figure 7. Spline-interpolated isocontour SSVEP amplitude topographies assessed via FFTs for Experiment 2. Amplitudes are averaged across the fundamental checkerboard flicker frequencies $(7.6,13.3$, and $17.8 \mathrm{~Hz})$ and cued red, green, and gray conditions. $\boldsymbol{a}$, SSVEP amplitude topographies. $\boldsymbol{b}$, SSVEP amplitude contrast topographies.

77.08, $\left.\mathrm{SE}=2.77 ; F_{(2,38)}=1.07, p=0.354, \eta^{2}=0.05\right)$. Again, as there was no reliable effect of cued color on behavioral performance and as EEG results for all color combinations were similar, subsequent analyses were pooled across this factor.

\section{Neural activity during conjunction search}

Consistent with Experiment 1, the checkerboard frequencies showed maximal responses over occipitoparietal sites, and this topographic focus was similar for all frequencies. SSVEP amplitudes were higher for the cued color compared with the uncued and baseline colors. Uncued and baseline colors showed similar topographies (Fig. 7a). The contrast topographies indicated that SSVEP amplitudes for the cued color were higher over both posterior and anterior electrode sites compared with uncued and baseline colors, whose topographies were highly similar (Fig. 7b). To assess apparent differences between colors at posterior sites, SSVEP amplitudes were averaged across the four electrodes $(\mathrm{POz}$, $\mathrm{Oz}, \mathrm{P} 2, \mathrm{O} 2$ ) with the strongest frequency-based responses on the grand average ERP.

To assess feature-based attentional modulation, SSVEP amplitudes $(\mu \mathrm{V})$ were submitted to a repeated-measures ANOVA with frequency $(7.6,13.3,17.8 \mathrm{~Hz})$ and color (cued, uncued, baseline) as factors. The frequency effect was nonsignificant $\left(F_{(2,38)}=1.92, p=0.161, \eta^{2}=0.09\right)$, indicating that each checkerboard frequency evoked similar SSVEP amplitudes. There was, however, a significant interaction between color and frequency $\left(F_{(4,76)}=3.88, p=0.006, \eta^{2}=0.17\right)$. The effect of color was significant at both $7.6 \mathrm{~Hz}\left(F_{(2,38)}=6.84, p=0.003, \eta^{2}=0.27\right.$; Fig. $8 a)$ and $13.3 \mathrm{~Hz}\left(F_{(2,38)}=4.48, p=0.018, \eta^{2}=0.19\right.$; Fig. $\left.8 b\right)$. In addition, at both frequencies, amplitudes were higher when that frequency was associated with the cued compared with base- 

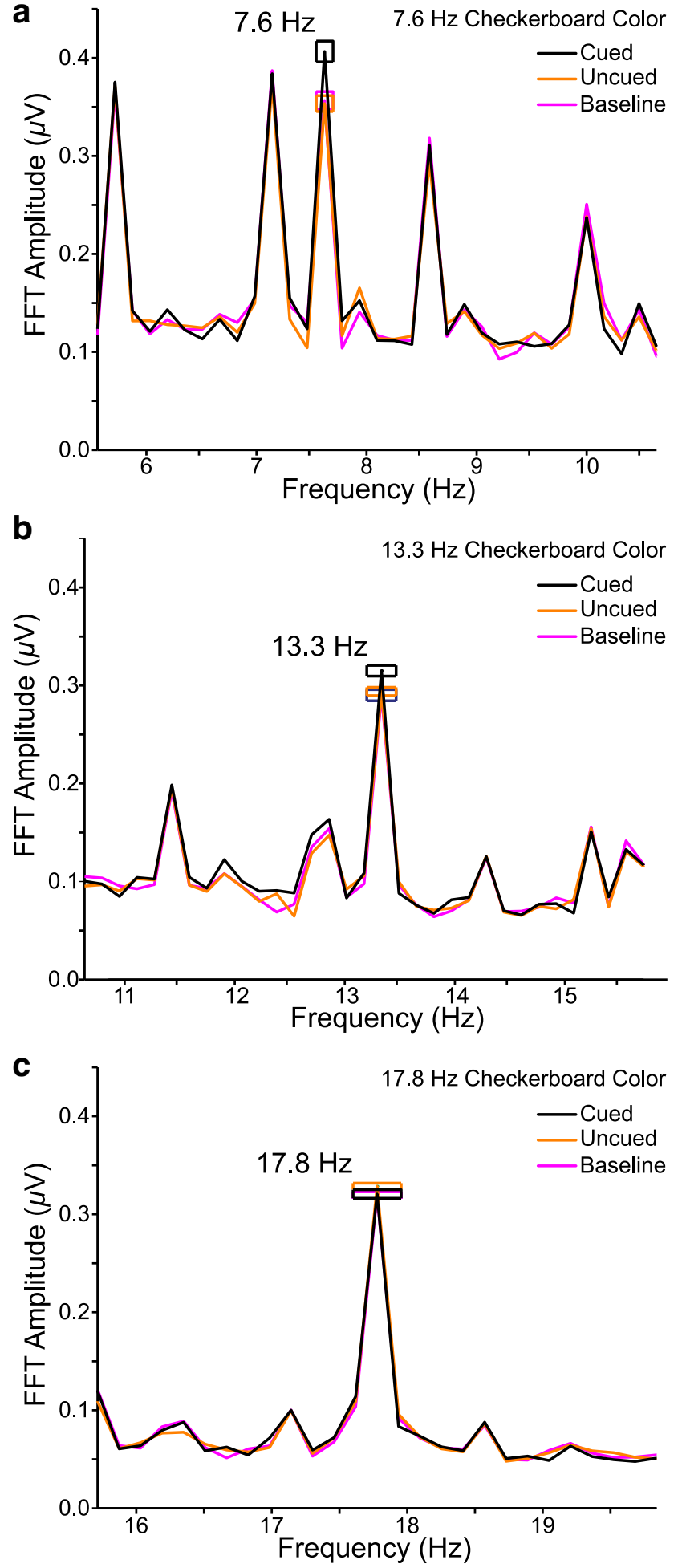

Figure 8. Checkerboard-evoked SSVEP amplitudes assessed via FFTs for Experiment 2. FFT amplitude spectra are averaged across a cluster of four occipitoparietal electrodes and all color combinations. Frequency spikes are located at the fundamental checkerboard frequencies and the search array harmonics. Error boxes represent within-subjects SE. $\boldsymbol{a}, 7.6 \mathrm{~Hz}$ amplitudes. $\boldsymbol{b}$, 13.3 $\mathrm{Hz}$ amplitudes. $\boldsymbol{c}, 17.8 \mathrm{~Hz}$ amplitudes.

line and uncued colors $\left(7.6 \mathrm{~Hz}: t_{(19)}=3.23, p=0.004 ; 13.3 \mathrm{~Hz}\right.$ : $\left.t_{(19)}=2.82, p=0.011\right)$. At both frequencies, there was no difference between uncued and baseline amplitudes $\left(7.6 \mathrm{~Hz}: t_{(19)}=\right.$ $\left.-0.23, p=0.818 ; 13.3 \mathrm{~Hz}: t_{(19)}=0.45, p=0.660\right)$. Color had no effect at $17.8 \mathrm{~Hz}\left(F_{(2,38)}=1.18, p=0.32, \eta^{2}=0.06\right.$; Fig. $\left.8 c\right)$. The lack of feature-based modulation at $17.8 \mathrm{~Hz}$ does not affect our interpretation of the results, as the color combinations were fully counterbalanced with checkerboard frequency. Also, in Experiment 1, higher SSVEPs for the cued color were limited to posterior electrode sites. The additional elevated responses at anterior sites in Experiment 2 might reflect increased demands on featurebased specificity arising from the addition of the baseline color (Scolari and Serences, 2010; Becker et al., 2013).

Together, the findings extend those of Experiment 1 by showing that feature-based selection outside a central search array reflects enhancement of target-defining features relative to distractor features. Distractor features, by contrast, are treated similarly regardless of whether they are present inside and outside the search array, or appear outside the array only.

To determine whether there might have been transient periods of suppression of the uncued color relative to the baseline color that our previous analyses failed to detect, we performed Morlet wavelet analyses to examine the amplitudes of the frequency-based responses over time. We extended the analysis window to encompass early-trial SSVEP responses and pooled the results over 7.6 and $13.3 \mathrm{~Hz}$ checkerboard frequencies, which showed statistically indistinguishable patterns of attentional modulation in the foregoing analysis. The wavelet analyses were successful in preserving amplitude modulation dynamics while separating responses for each color from the harmonic responses associated with the central search arrays (Fig. 9a). Responses to the cued, uncued, and baseline colors became prominent $\sim 2-3 \mathrm{~s}$ into the trial. Consistent with the main analysis, these responses were strongest for the cued color relative to the uncued and baseline colors. Uncued and baseline colors showed similar responses throughout the trial (Fig. 9b,c).

To assess these patterns, we performed permutation tests on the period from checkerboard onset $(2.1 \mathrm{~s})$ to the end of the trial (Fig. $9 d$ ). There were no significant differences in responses (MCA) for the uncued and baseline colors, indicating that there was no time period within the trial during which the uncued color was suppressed relative to baseline. By contrast, there were two temporally distinct periods of significant feature-based enhancement (at $\sim 2.0$ $3.0 \mathrm{~s}$ and again at $\sim 5.5-8.5 \mathrm{~s}$ ) during which the cued color evoked significantly larger responses than the uncued and baseline colors. These results confirm that feature-based modulation outside the array during conjunction search reflects enhancement of the cued color in the absence of suppression of the uncued color.

\section{Discussion}

We investigated how the demands of unique-feature and conjunction search tasks influence neural activity for stimuli at ignored locations beyond the spatial extent of the search array. Experiment 1 compared an easy unique-feature search with a difficult conjunction search. During conjunction but not uniquefeature search, checkerboards outside the array that matched the cued color evoked enhanced oscillations relative to those with the uncued color. Additionally, responses outside the array were reduced during conjunction compared with unique-feature search. Experiment 2 was designed to test whether feature-based modulation outside the search array involved enhancement, suppression, or both. We used a conjunction task but now included three different combinations of checkerboard, thus affording a baseline with which to compare responses to cued and uncued colors. We found that the cued color evoked enhanced oscillations relative to uncued and baseline colors, whereas responses to uncued and baseline colors were not reliably different. The baseline color appeared less frequently within the visual field. This might have 

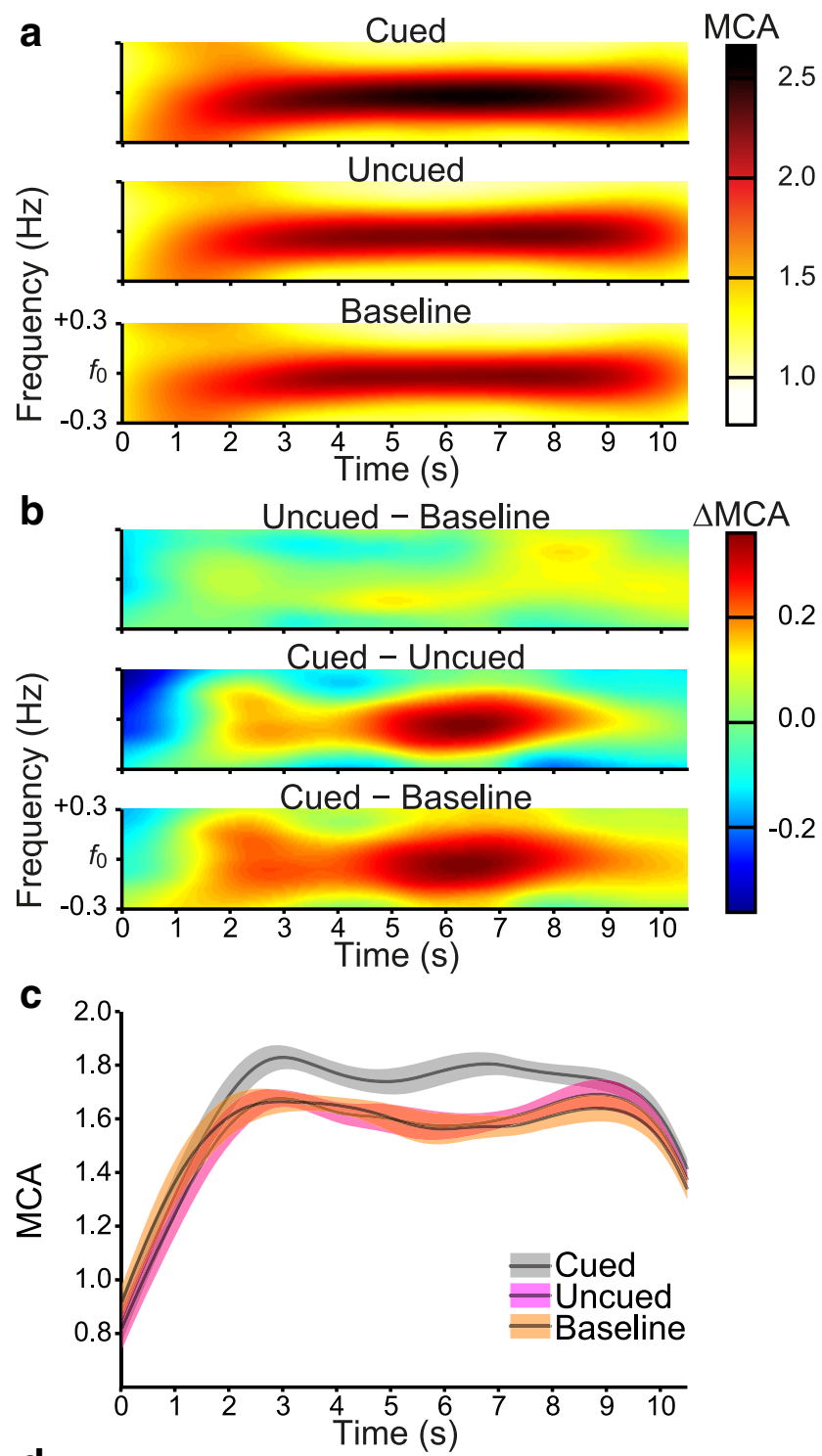

d

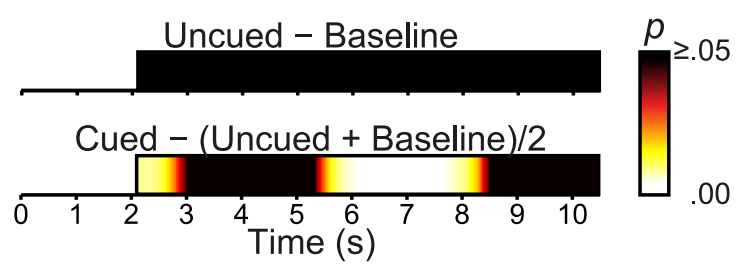

Figure 9. Morlet wavelet time-frequency analyses of attentional modulation in Experiment 2. Results reflect the average of $7.6 \mathrm{~Hz}$ and $13.3 \mathrm{~Hz}$ checkerboard frequencies and are plotted from cue onset to the final search array offset. $\boldsymbol{a}$, Wavelet heat maps. $\boldsymbol{b}$, Wavelet contrast heat maps. c, Wavelet amplitudes averaged over the range $f_{0} \pm 0.24 \mathrm{~Hz}$ ( $f_{0}=$ fundamental checkerboard frequency). Error shading represents within-subjects SE. $\boldsymbol{d}$, Permutation $t$ tests conducted at each time point from flicker onset (2.1 s). Only significant differences corrected for family-wise error rate are presented $(p<0.05)$.

diminished sensory adaptation for this color relative to the other colors, which in turn might have obscured task-related enhancement rather than task-related suppression. Consequently, the less frequent appearance of the baseline color does not alter our conclusions. Collectively, the two experiments show that featurebased selection outside a search array depends upon the relative demands of the search task and reflects feature-based enhancement of target properties without feature-based suppression of distractor properties.
Previously, Bichot et al. (2005) demonstrated how featurebased and spatial attention interact during search. Monkeys freely scanned arrays to locate a feature-defined target (based on shape or color). Throughout the search, neurons representing saccade targets produced enhanced responses, reflecting spatial selection. In addition, neurons that were not selected for saccades, but that responded to target-defining features, also produced enhanced responses, suggesting featural selection. Our population-level results extend the work of Bichot et al. (2005) by demonstrating that search demands within the array influence neural responses to objects outside the array.

Our demonstration of feature-based enhancement is notable given our experimental design constrained spatial attention to the central array. First, the checkerboards were completely and always task-irrelevant and thus could be ignored (compare Andersen et al., 2008). Second, the checkerboards were subject to strong competition from the central array (compare Andersen et al., 2011). Finally, neural responses to the objects outside the array were degraded by virtue of appearing in peripheral vision (Sereno et al., 1995). Taking all these factors into account, we conclude that it is unlikely that feature-based attention can be restricted to a circumscribed region within the visual field during conjunction search (Adamo et al., 2010).

Does the absence of feature-based selection outside the array during unique-feature search imply that feature-based attention does not spread to irrelevant locations under such conditions, or does it suggest instead the absence of feature-based selection within the central array itself? Our results are most consistent with the latter possibility. However, it does appear that the unique-feature search was aided by top-down control. Specifically, among our other results, the P1 peak occurring $\sim 100 \mathrm{~ms}$ after array onset was enhanced by the appearance of the target feature in the contralateral visual field. This enhancement occurred earlier than that associated with attentional capture by salient, task-irrelevant singletons and as early as effects attributed to top-down control (Hillyard and Münte, 1984; Zhang and Luck, 2009; Moher et al., 2014). Thus, the most parsimonious explanation is that unique-feature search was guided by a topdown control setting that highlights salient items, regardless of their features (Folk et al., 2002; Leber and Egeth, 2006).

Our results clearly demonstrate that attentional modulation outside the array depends on the relative demands of the search task. It might be argued that the increased difficulty of the conjunction search resulted in feature-based enhancement outside the array and that this was not observed during unique-feature search as the latter task was too easy. Our view, however, is that the difficulty difference between these tasks remains the fact to be explained rather than the explanatory factor (Wolfe and Horowitz, 2004). First, difficulty alone cannot characterize categories of search (Wolfe, 1998). Searches can produce similar behavioral performance but rely on different mechanisms. Second, differences between unique-feature and conjunction searches cannot be reduced to differences in difficulty. Although many conjunction searches are difficult and many unique-feature searches are easy, there are easy conjunction searches and difficult uniquefeature searches (Wolfe, 1998).

All things considered, differences in neural competition arising from within the array probably underlie the observed patterns for our search tasks. Indeed, competition was likely greater in the conjunction relative to unique-feature task in three ways. First, array elements with the uncued feature were more effective competitors in conjunction search, as there were equal numbers of array items with the cued and uncued features. Second, the num- 
ber of elements with the cued feature within the array exceeded the four item capacity of visual short-term working memory (Cowan, 2001) during conjunction but not unique-feature search. Third, the conjunction search task required that the search target be discriminated from similar elements with a different combination of features. This notion is related to the concept of feature binding, which has been invoked to explain conjunction search performance (Treisman and Gelade, 1980).

From the present results, we can make a suggestion as to the circumstances in which feature-based attention will apply outside the target array during visual search. It has been suggested that feature-based attention is particularly useful when searching for feature-defined targets (Maunsell and Treue, 2006). We add the important caveat that feature-based attention during visual search additionally requires competition between target and distractor items within the array. The biasing effects of attention are maximal when multiple competing stimuli are present (Desimone and Duncan, 1995). During our conjunction search, there was substantial competition between items. By contrast, our unique-feature search involved only minimal competition, so the target tended to "pop-out" of the display.

Our finding of feature-based enhancement rather than suppression is consistent with work emphasizing the importance of this operation and attention-guiding features during visual search (Wolfe, 1994). Feature-based attention, though, can involve both enhancement and suppression (e.g., Treue and Martínez Trujillo, 1999). Recently, Andersen and Müller (2010) investigated the time course of feature-based enhancement and suppression using EEG and frequency tagging. In their task, fields of red and blue dots flickered at unique frequencies, and participants were cued to detect periods of coherent motion in one of the fields. After the cue, frequency-tagged responses to the cued dots were enhanced, whereas responses to the uncued dots were suppressed. There are a number of key differences between the present study and that of Andersen and Müller (2010). For instance, Andersen and Müller (2010) investigated how ongoing neural responses in central vision were affected by transient attention shifts for the purpose of motion detection. By contrast, we focused on neural responses to irrelevant stimuli in peripheral vision during sustained search at the fovea. One possibility is that feature-based suppression applies to objects within the spatial focus of attention, but not to objects at ignored and completely task-irrelevant locations. Another possibility is that search itself relies more on enhancement of target-related features than on suppression of distractors. A third possibility is that both enhancement and suppression are necessary during attention shifts, whereas enhancement may be more important during sustained attention. Alternatively, sustained attention may facilitate featurebased suppression (Moher et al., 2014). An important goal of future research will be to examine which attentional tasks require feature-based enhancement, suppression, or a combination of both.

Many visual attention tasks involve interactions between spatial and feature-based attention. An influential proposal, the feature-gain similarity model (Treue and Martínez Trujillo, 1999), posits that neural responses to visual stimuli depend on their similarity with the target and the response selectivity of the neuron. Responses are thought to be enhanced for neurons whose selectivity matches the current target feature or location (compare with Scolari and Serences, 2010; Becker et al., 2013). Under this model, spatial location is treated in the same manner as "classic" visual features, such as color. An important prediction is that feature-based attention and spatial attention produce additive or multiplicative effects on neuronal response gain (Treue and Martínez Trujillo, 1999; Andersen et al., 2011). The current results suggest, however, that space-feature interactions can be more complex. During unique-feature search, neural responses outside the array were strong and unaffected by featurebased attention. By contrast, during conjunction search these responses were reduced and were also subject to feature-based enhancement. This suggests that spatial attention and feature-based attention may interact to produce emergent solutions to visual competition problems that reflect more than simple additivity.

In conclusion, we investigated how neural responses to ignored stimuli in peripheral vision are influenced by the demands of central visual search. Feature-based attention applied outside the search array during conjunction, but not during uniquefeature search. This suggests that feature-based enhancement of stimuli at ignored locations depends critically on competition between objects within the search array. Under such conditions of competition, it may be difficult to restrict feature-based selection to a circumscribed region within the visual field.

\section{References}

Adamo M, Pun C, Ferber S (2010) Multiple attentional control settings influence late attentional selection but do not provide an early attentional filter. Cogn Neurosci 1:102-110. CrossRef Medline

Andersen SK, Müller MM (2010) Behavioral performance follows the time course of neural facilitation and suppression during cued shifts of featureselective attention. Proc Natl Acad Sci U S A 107:13878-13882. CrossRef Medline

Andersen SK, Hillyard SA, Müller MM (2008) Attention facilitates multiple stimulus features in parallel in human visual cortex. Curr Biol 18:10061009. CrossRef Medline

Andersen SK, Fuchs S, Müller MM (2011) Effects of feature-selective and spatial attention at different stages of visual processing. J Cogn Neurosci 23:238-246. CrossRef Medline

Andersen SK, Müller MM, Martinovic J (2012) Bottom-up biases in feature-selective attention. J Neurosci 32:16953-16958. CrossRef Medline

Becker SI, Folk CL, Remington RW (2013) Attentional capture does not depend on feature similarity, but on target-nontarget relations. Psychol Sci 24:634-647. CrossRef Medline

Bichot NP, Rossi AF, Desimone R (2005) Parallel and serial neural mechanisms for visual search in macaque area V4. Science 308:529-534. CrossRef Medline

Blair RC, Karniski W (1993) An alternative method for significance testing of waveform difference potentials. Psychophysiology 30:518-524. CrossRef Medline

Bridwell DA, Srinivasan R (2012) Distinct attention networks for feature enhancement and suppression in vision. Psychol Sci 23:1151-1158. CrossRef Medline

Buschman TJ, Miller EK (2007) Top-down versus bottom-up control of attention in the prefrontal and posterior parietal cortices. Science 315: 1860-1862. CrossRef Medline

Corbetta M, Shulman GL (2002) Control of goal-directed and stimulusdriven attention in the brain. Nat Rev Neurosci 3:201-215. CrossRef Medline

Cortese F, Bernstein LJ, Alain C (1999) Binding visual features during highrate serial presentation. Neuroreport 10:1565-1570. CrossRef Medline

Cowan N (2001) The magical number 4 in short-term memory: a reconsideration of mental storage capacity. Behav Brain Sci 24:87-114, discussion 114-185. CrossRef Medline

Delorme A, Makeig S (2004) EEGLAB: an open source toolbox for analysis of single-trial EEG dynamics including independent component analysis. J Neurosci Methods 134:9-21. CrossRef Medline

Desimone R, Duncan J (1995) Neural mechanisms of selective visual attention. Annu Rev Neurosci 18:193-222. CrossRef Medline

Donner TH, Kettermann A, Diesch E, Ostendorf F, Villringer A, Brandt SA (2002) Visual feature and conjunction searches of equal difficulty engage only partially overlapping frontoparietal networks. Neuroimage 15:1625. CrossRef Medline

Dowdall JR, Luczak A, Tata MS (2012) Temporal variability of the N2pc 
during efficient and inefficient visual search. Neuropsychologia 50:24422453. CrossRef Medline

Eimer M, Kiss M (2008) Involuntary attentional capture is determined by task set: evidence from event-related brain potentials. J Cogn Neurosci 20:1423-1433. CrossRef Medline

Farge M (1992) Wavelet transforms and their applications to turbulence. Annu Rev Fluid Mech 24:395-457. CrossRef

Folk CL, Leber AB, Egeth HE (2002) Made you blink! Contingent attentional capture produces a spatial blink. Percept Psychophys 64:741-753. CrossRef Medline

Gregoriou GG, Gotts SJ, Zhou H, Desimone R (2009) High-frequency, long-range coupling between prefrontal and visual cortex during attention. Science 324:1207-1210. CrossRef Medline

Groppe DM, Urbach TP, Kutas M (2011a) Mass univariate analysis of event-related brain potentials/fields: II. Simulation studies. Psychophysiology 48:1726-1737. CrossRef Medline

Groppe DM, Urbach TP, Kutas M (2011b) Mass univariate analysis of event-related brain potentials/fields: I. A critical tutorial review. Psychophysiology 48:1711-1725. CrossRef Medline

Herrmann CS, Rach S, Vosskuhl J, Strüber D (2013) Time-frequency analysis of event-related potentials: a brief tutorial. Brain Topogr. Advance online publication. Retrieved Nov. 6, 2013. doi:10.1007/s10548-0130327-5. CrossRef Medline

Hickey C, McDonald JJ, Theeuwes J (2006) Electrophysiological evidence of the capture of visual attention. J Cogn Neurosci 18:604-613. CrossRef Medline

Hillyard SA, Münte TF (1984) Selective attention to color and location: an analysis with event-related brain potentials. Percept Psychophys 36:185198. CrossRef Medline

Hubel DH, Wiesel TN (1962) Receptive fields, binocular interaction and functional architecture in the cat's visual cortex. J Physiol 160:106-154. Medline

Kim YJ, Grabowecky M, Paller KA, Muthu K, Suzuki S (2007) Attention induces synchronization-based response gain in steady-state visual evoked potentials. Nat Neurosci 10:117-125. CrossRef Medline

Lavie N (1995) Perceptual load as a necessary condition for selective attention. J Exp Psychol Hum Percept Perform 21:451-468. CrossRef Medline

Leber AB, Egeth HE (2006) It's under control: top-down search strategies can override attentional capture. Psychon Bull Rev 13:132-138. CrossRef Medline

Leonards U, Palix J, Michel C, Ibanez V (2003) Comparison of early cortical networks in efficient and inefficient visual search: an event-related potential study. J Cogn Neurosci 15:1039-1051. CrossRef Medline

Lien MC, Ruthruff E, Goodin Z, Remington RW (2008) Contingent attentional capture by top-down control settings: converging evidence from event-related potentials. J Exp Psychol Hum Percept Perform 34:509530. CrossRef Medline

Luck SJ, Hillyard SA (1994a) Electrophysiological correlates of feature analysis during visual search. Psychophysiology 31:291-308. CrossRef Medline

Luck SJ, Hillyard SA (1994b) Spatial filtering during visual search: evidence from human electrophysiology. J Exp Psychol Hum Percept Perform 20: 1000-1014. CrossRef Medline

Luck SJ, Hillyard SA (1995) The role of attention in feature detection and conjunction discrimination: an electrophysiological analysis. Int J Neurosci 80:281-297. CrossRef Medline

Luck SJ, Fan S, Hillyard SA (1993) Attention-related modulation of sensory-evoked brain activity in a visual search task. J Cogn Neurosci 5:188-195. CrossRef Medline

Masson ME, Loftus GR (2003) Using confidence intervals for graphically based data interpretation. Can J Exp Psychol 57:203-220. CrossRef Medline

Maunsell JH, Treue S (2006) Feature-based attention in visual cortex. Trends Neurosci 29:317-322. CrossRef Medline

Moher J, Lakshmanan BM, Egeth, HE, Ewen JB (2014) Inhibition drives early feature-based attention. Psychol Sci. Advance online publication. Retrieved Jan. 3, 2014. doi:10.1177/0956797613511257. CrossRef Medline

Moran J, Desimone R (1985) Selective attention gates visual processing in the extrastriate cortex. Science 229:782-784. CrossRef Medline

Morgan ST, Hansen JC, Hillyard SA (1996) Selective attention to stimulus location modulates the steady-state visual evoked potential. Proc Natl Acad Sci U S A 93:4770-4774. CrossRef Medline

Nobre AC, Coull JT, Walsh V, Frith CD (2003) Brain activations during visual search: contributions of search efficiency versus feature binding. Neuroimage 18:91-103. CrossRef Medline

Oostenveld R, Praamstra P (2001) The five percent electrode system for high-resolution EEG and ERP measurements. Clin Neurophysiol 112: 713-719. CrossRef Medline

Oostenveld R, Fries P, Maris E, Schoffelen JM (2011) FieldTrip: open source software for advanced analysis of MEG, EEG, and invasive electrophysiological data. Comput Intell Neurosci 2011:156869. CrossRef Medline

Sawaki R, Geng JJ, Luck SJ (2012) A common neural mechanism for preventing and terminating the allocation of attention. J Neurosci 32:1072510736. CrossRef Medline

Schwartz S, Vuilleumier P, Hutton C, Maravita A, Dolan RJ, Driver J (2005) Attentional load and sensory competition in human vision: modulation of fMRI responses by load at fixation during task-irrelevant stimulation in the peripheral visual field. Cereb Cortex 15:770-786. CrossRef Medline

Scolari M, Serences JT (2010) Basing perceptual decisions on the most informative sensory neurons. J Neurophysiol 104:2266-2273. CrossRef Medline

Serences JT, Shomstein S, Leber AB, Golay X, Egeth HE, Yantis S (2005) Coordination of voluntary and stimulus-driven attentional control in human cortex. Psychol Sci 16:114-122. CrossRef Medline

Sereno MI, Dale AM, Reppas JB, Kwong KK, Belliveau JW, Brady TJ, Rosen BR, Tootell RB (1995) Borders of multiple visual areas in humans revealed by functional magnetic resonance imaging. Science 268:889-893. CrossRef Medline

Sibson R (1981) A brief description of natural neighbour interpolation. In: Interpreting multivariate data (Barnett V, ed), pp 21-36. Chichester, United Kingdom: Wiley.

Soria R, Srebro R (1996) Event-related potential scalp fields during parallel and serial visual searches. Cogn Brain Res 4:201-210. CrossRef Medline

Treisman AM, Gelade G (1980) A feature-integration theory of attention. Cogn Psychol 12:97-136. CrossRef Medline

Treue S, Martínez Trujillo JC (1999) Feature-based attention influences motion processing gain in macaque visual cortex. Nature 399:575-579. CrossRef Medline

Wolber M, Wascher E (2003) Visual search strategies are indexed by eventrelated lateralizations of the EEG. Biol Psychol 63:79-100. CrossRef Medline

Wolfe JM (1994) Guided search 2.0 a revised model of visual search. Psychon Bull Rev 1:202-238. CrossRef Medline

Wolfe JM (1998) What can 1 million trials tell us about visual search? Psychol Sci 9:33-39. CrossRef

Wolfe JM, Horowitz TS (2004) What attributes guide the deployment of visual attention and how do they do it? Nat Rev Neurosci 5:495-501. CrossRef Medline

Zhang W, Luck SJ (2008) Feature-based attention modulates feedforward visual processing. Nat Neurosci 12:24-25. CrossRef Medline 